\title{
Empresas familiares frente a las crisis
}

\section{Small family businesses facing economic crises}

\author{
María Guadalupe Serna*
}

\begin{abstract}
This article undertakes a reflection on the effects of the Mexican crises of 1984-1985 and 1994-1995 for a small group of family enterprises located in Aguascalientes City. I explore the kind of resources, tangible and intangible assets, which were available to their owners during these periods; what kind of support they had access to, and how they responded and adapted to harsh economic conditions. I also analy$z e$ the different kinds of actions taken by owners to deal with the crises and how these gave impetus to, or hindered, their business project. I use the concept of social capital to explain the various conditions under which small family firms arose and developed, as well as their possibilities for success in crisis conditions.
\end{abstract}

Keywords: social networks, family support, small family businesses, economic crisis, social capital.

\section{Resumen}

En este artículo llevo a cabo una reflexión sobre los efectos de las crisis de 19841985 y 1994-1995 en un pequeño grupo de empresas familiares localizadas en la ciudad de Aguascalientes. Exploro el tipo de recursos tangibles e intangibles con los que contaban sus propietarios durante esos periodos, los apoyos que tenían a su disposición, así como las distintas formas en que respondieron y se adaptaron a las condiciones económicas prevalecientes. Analizo las distintas acciones adoptadas por los propietarios para hacer frente a las condiciones económicas prevalecientes, así como la forma en que algunas veces la crisis en puerta impulsó o bien obstaculizó el proyecto empresarial. Para ello empleo el concepto de capital social que resulta de gran utilidad para explicar las diversas condiciones en que surgen y se desarrollan las pequeñas empresas familiares, así como sus distintas posibilidades de éxito en condiciones de crisis.

Palabras clave: redes sociales, apoyo familiar, empresas familiares, crisis económica, capital social.

\footnotetext{
* Instituto José María Luis Mora, México. Correo-e: gserna@mora.edu.mx.
} 


\section{Introducción}

Desde la década de los ochenta la economía mexicana ha enfrentado crisis económicas recurrentes en donde han sido las empresas familiares, especialmente las de tamaño micro y pequeñas, las más afectadas por una situación que se ha extendido durante más de dos décadas. La crisis de 1985 dejó sentir sus efectos en el sector empresarial, y a este evento le siguió un corto periodo de crecimiento, hasta el error de diciembre de 1994 que derivó en una crisis aparentemente más profunda que la anterior. De hecho, en el periodo comprendido entre 1970 y 1990 la proporción porcentual de la PEA empresarial disminuyó de manera alarmante y apenas se incrementó en el año 2000, sin lograr recuperar la proporción porcentual que se tenía tres décadas atrás. ${ }^{1}$ Con el nuevo milenio la población mexicana supuso que al fin ingresaríamos a un periodo de crecimiento sostenido, y con ello a la urgente proliferación de empresas y su consecuente generación de empleos. Que finalmente contaríamos con una política económica donde se delinearan las áreas sobre las que se impulsaría el crecimiento y se fortalecería a las empresas familiares para volverlas altamente competitivas. Sin embargo esto no sucedió, y en 2008 sufrimos el siguiente efecto económico que desencadenó una tercera crisis, aparentemente más aguda que las anteriores, por su carácter global. Para 2009 el secretario de Economía en turno informó que la mortandad empresarial había iniciado y afectaba una vez más a las empresas familiares de tamaño micro y pequeño. Los resultados del censo de 2010 seguramente reflejarán de nuevo un decremento en las actividades empresariales, es decir, como sucedió en las crisis precedentes, los programas de apoyo a las empresas parecen haber llegado de nueva cuenta con retraso. Cómo han transitado por esta nueva crisis económica las empresas es algo que aún debemos investigar, por ahora una posibilidad es analizar qué le sucedió a algunas empresas manufactureras en las crisis de finales del siglo xx.

Con este texto se busca analizar, a partir de la trayectoria de un pequeño grupo de empresas familiares en Aguascalientes, cómo transitaron y en qué condiciones sobrevivieron a dos crisis económicas: las de 1984-1985 y 1994-1995, respectivamente. Analizo el tipo de recursos tangibles e intangibles, esto es, el capital económico, social y cultural con que contaron los empresarios y las características de las redes de soporte que los apoyaron durante estos ciclos de inestabilidad. En los casos presentados analizo la manera en que los empresarios fortalecieron o no lograron el fortalecimiento de sus redes de colaboración y soporte durante las crisis de 1985

\footnotetext{
${ }^{1}$ Más adelante se analiza de manera detallada lo que sucedió en este periodo en relación con la PEA empresarial.
} 
y 1995. Conocer las fallas de previsión y/o aprendizajes logrados en estos ciclos de inestabilidad puede contribuir a explicar lo que podemos esperar en el contexto de incertidumbre económica actual. En la exposición de los casos también se hace evidente la desconfianza de los empresarios hacia el aparato gubernamental y la banca, al igual que el desconocimiento de ese sector respecto de sus derechos para demandar la puesta en marcha de políticas económicas de rápida respuesta y largo plazo, por parte del Estado. Para 1999 las empresas analizadas seguían en operaciones, aunque en condiciones distintas cada una de ellas, unas fortalecidas, otras sin lograr consolidarse.

Desde mi punto de vista, el acercamiento a este tipo de reflexiones puede ser relevante en un contexto como el actual de profunda crisis económica global-local, donde prevalece la incertidumbre respecto del destino que tendrán las miles de micro y pequeñas empresas que operan en México: sus gestores, familias y trabajadores. En contextos de aguda crisis, como el actual, se evidencia la dificultad que tienen las entidades gubernamentales responsables para poner en marcha políticas económicas eficientes y de largo plazo, para el heterogéneo contingente que conforman las micro y pequeñas empresas en México. Hasta ahora, a fines del año 2010 , no se ha logrado que este conjunto avance en un proceso de mejora continua que beneficie a los involucrados inmediatos, así como a las regiones donde las empresas se localizan.

Parto del supuesto de que el proceso de gestación, desarrollo y consolidación de una empresa es resultado de una decisión personal enraizada en un compromiso de carácter social. Cuando una persona incursiona en la actividad empresarial, su decisión tiene efectos directos en su núcleo familiar y se extiende al conjunto de relaciones que el gestor del proyecto teje, mientras la empresa se mantiene en operaciones. De igual manera la empresa coadyuva al desarrollo de la región y ésta última a la empresa, lo que genera un relación de interdependencia (Serna, 2003). Utilizo el concepto de capital social que ha demostrado su relevancia para explicar el éxito relativo que pueden tener los actores -en este caso económicospara lograr el desarrollo de su empresa (Bourdieu, 1985; Portes, 1999). La construcción de redes de apoyo que se capitalizan permite que los actores, en este caso los empresarios, logren el acceso a una diversidad de recursos económicos, así como al incremento de su capital cultural mediante el contacto con la experiencia de otros, lo que resulta fundamental para el sostenimiento de una empresa.

Divido el texto en cuatro secciones. En la primera hago una revisión de los conceptos empleados en el análisis; en la segunda discuto brevemente el ambiente de las últimas dos décadas del siglo xx en México y en Aguascalientes, sus cambios y efectos en las empresas. En la tercera sección 
analizo dos empresas familiares en las que se hace patente cómo se construyó el entramado de redes de apoyo que cristalizó en capital social. Enfatizo la relevancia que tuvo, para el proyecto económico, contar con un capital cultural expresado vía un conjunto de conocimientos efectivos que apoyaron su consolidación. En la cuarta y última sección analizo dos empresas familiares cuyo desarrollo contrasta con las anteriores, pues se destacan las enormes dificultades para construir un entramado de redes de apoyo que se traduzca en capital social y cómo esto obstaculiza la consolidación del proyecto económico. También se pone al descubierto que la combinación de conocimientos precarios y un entorno que no facilita la adquisición de nuevas prácticas, se vuelve un obstáculo que impide el desarrollo de la empresa

\section{Los casos y su método de análisis}

Los casos de las empresas que analizo en este texto se recopilaron entre septiembre y noviembre de 1999 en la ciudad de Aguascalientes. El propósito de la investigación fue explorar la manera en que los empresarios hidrocálidos respondieron al llamado del gobierno estatal para participar en los distintos programas de financiamiento para las micro y pequeñas empresas puestos en marcha en ese periodo. Indagar si ese sector empresarial tenía conocimiento de los mismos, el tipo de información con que contaban respecto de los programas, qué razones mencionaron para solicitar financiamiento, y si habían obtenido en otras ocasiones apoyo económico y de dónde había provenido. Encontramos que, en la mayoría de los casos, los empresarios entrevistados tenían una percepción más favorable de su entorno, pues la crisis de 1994-1995 había pasado. En tanto que los funcionarios de los gobiernos estatal y municipal responsables de la puesta en marcha de esa política económica, se enfocaban a impulsar la actividad empresarial en Aguascalientes.

Durante el trabajo de campo se realizaron 10 entrevistas a profundidad a empresarios ${ }^{2}$ de la localidad en la industria manufacturera que hubieran estado en actividad por más de una década. También se exploró el tipo de necesidades económicas que tuvieran y si, en razón de esto, habían decidido involucrarse en los programas de apoyo ofrecidos. No hubo especificaciones respecto del tamaño de la empresa. En todas las entrevistas se recopiló información sobre el perfil sociodemográfico del empresario y los miembros de su familia; sobre la trayectoria de la empresa, número de trabajadores y procesos de reestructuración a lo largo de su

\footnotetext{
${ }^{2}$ Para ese estudio se entrevistó también a funcionarios de los gobiernos estatal y municipal, aunque en este texto no me ocupo de ellos.
} 
ciclo productivo. Asimismo se reunió información sobre la manera en que iniciaron operaciones y los apoyos económicos y sociales recibidos, y también se exploró a quiénes se recurría ante un problema de liquidez. Se averiguó sobre proveedores y cómo habían establecido contacto y, finalmente, se recopiló información sobre procesos de comercialización, dónde vendían sus productos, así como el tipo de problemas y formas de solución que hubieran tenido con su clientela.

Todas las empresas de las que se recabó información eran familiares, habían contado con el apoyo de su grupo familiar desde su inicio y en todos los casos uno o varios miembros del grupo participaban directamente en el negocio como trabajadores o en algún cargo específico. Este hecho vino a confirmar una vez más que el componente familiar en las empresas hidrocálidas ha sido muy importante (Serna, 2003). El tiempo de operación de las empresas oscilaba entre 16 y 25 años, es decir, habían sobrevivido a las dos crisis económicas previas con efectos muy diferentes para cada una de éstas. Seis eran microempresas y contaban con entre seis y 12 trabajadores, las otras cuatro eran empresas pequeñas con entre $18 \mathrm{y}$ 80 trabajadores. Todas pertenecían a la industria manufacturera, por ejemplo, a la fabricación de materias primas como hilos, para la industria del bordado, elaboración de ropa de punto, al bordado y deshilado, a la confección de prendas de vestir, o bien de artículos de carnaza, muebles, cerámicas, así como al diseño de productos de acero e incluso a la producción agrícola. Dos de estas empresas producían para el mercado regional y las otras ocho comercializaban sus productos en mercados regionales y extrarregionales, de estas últimas, dos exportaban una parte de su producción. Prácticamente todas las empresas resintieron el efecto de la crisis de los ochenta, aunque consideraban que la afectación fue mayor en la de los noventa. Todas tuvieron cambios que las mantuvieron en la precariedad o las enfilaron hacia un proceso de consolidación con posibilidades de lograr su reproducción. Tres empresas habían reestructurado sus operaciones en los noventa y se transformaron en sociedades anónimas.

De este conjunto de casos seleccioné cuatro empresas familiares que considero cubren todos los ángulos sobre los que me propongo reflexionar en este texto, por tanto, se trata de casos contrastantes. Dos de ellos permiten esclarecer la manera en que las empresas transitaron por las fases de crisis económica y cómo el tipo de recursos tangibles e intangibles con que contaron contribuyeron a su fortalecimiento. En contraste, en los otros dos casos se analizan las dificultades que envolvieron a los propietarios que carecían de un capital cultural que los acompañara en la creación y desarrollo de sus empresas. El obstáculo que representó para ellos carecer de apoyos tangibles, pero especialmente intangibles, durante los ciclos de crisis económica y cómo esta situación las mantuvo en la precariedad. 


\section{Discusión conceptual}

De las diferentes perspectivas para estudiar al empresariado, una que me parece pertinente para este análisis es la que ha puesto el acento en las relaciones específicas entre el actor y la situación social (Martinelli, 1994) y que desarrolló Barth (1967) y utilizaron Curran y Borrows (1987) y Goffe y Scase (1985) en su análisis sobre las mujeres de empresa. En este tipo de trabajos la preocupación fundamental ha sido tratar de establecer qué hace un empresario en el nivel micro en términos de las estructuras de oportunidades cambiantes. Para esta postura, los actores económicos realizan un análisis de sus opciones y toman decisiones en contextos sociales que se modifican de manera constante, y al examinar las oportunidades existentes o las que surgen en el tiempo toman ventaja de ellas, y no las dejan para otros. Este tipo de análisis establece una relación entre dos niveles: el macro de la estructura social -las características de la estructura de oportunidades- y el micro, caracterizado por lo que el individuo decide y está en posibilidades de hacer-sus acciones concretas-. Se ve entonces al empresariado en términos de las situaciones individuales que enfrenta, así como las de los grupos sociales a los que pertenecen, lo que implica también que no hay un modelo único de empresario. Como será factible apreciar en este análisis, todos los empresarios responden y toman decisiones en contextos específicos donde responden a dos niveles: el macro de la estructura y contexto general y el micro, es decir, su situación concreta, que al combinarse producen un efecto que suele ser muy diferente para cada caso.

Respecto de la definición de empresario, éstos son actores preocupados por promover unidades económicas, por desarrollarlas y consolidarlas, y al construirlas buscan que sean acordes con las necesidades de la actividad productiva, comercial o de servicios donde los proyectos se insertan y donde han logrado un nicho para ellos. Son actores sociales y económicos preocupados por ser innovadores en la medida de sus posibilidades, toman riesgos constantes al iniciar sus actividades y al buscar colocar sus productos, bienes o servicios en el mercado. Cuando comienzan un proceso buscan hacer uso de los recursos económicos y sociales que tienen a su alcance, en virtud de las relaciones que tienen con el grupo o los grupos con que interactúan, y lo harán de manera que esto conlleve un beneficio para su actividad económica (Serna, 2003: 60-61). Como actores económicos necesitan construir relaciones sociales y económicas, y el entramado que ellos tejan será lo que les permita, en buena medida, concretar sus propósitos y desarrollar sus proyectos. Este tejido de relaciones ha sido estudiado a partir de las redes sociales en el sentido propuesto por Polan- 
yi (1968), donde se analizan las formas de transición e intercambio de recursos, trabajos, bienes y servicios en una sociedad.

También se ha estudiado a partir del concepto de capital, cuya propuesta teórica inicial formularon Bourdieu (1985) y Coleman (1993), la cual se centra en los individuos o pequeños grupos como unidades de análisis. En las últimas dos décadas este concepto se ha vuelto muy popular entre los sociólogos, aunque de acuerdo Portes (1999), sin ofrecer nuevas ideas que no sean las que se refieren a constatar que involucrarse y participar en grupos puede tener consecuencias positivas para los individuos y los grupos. El poder heurístico de este concepto proviene de su preocupación por enfocar la atención en las consecuencias positivas de la sociabilidad y colocarlas en una discusión mayor de capital que enfatiza cómo esta forma no monetaria puede ser una fuente importante de poder e influencia (Portes y Landolt, 2000). La amplitud de este concepto refleja una característica primordial de la vida social, que implica que los lazos sociales de cualquier tipo se pueden utilizar con relativa frecuencia para diferentes propósitos (Adler y Kwon, 2002). Estos recursos de capital social descansan -como muchos otros- en la estructura social en que los actores sociales se ubican. De acuerdo con Adler y Kwon (2002), podemos diferenciar el capital social de otro tipo de recursos a partir de la dimensión específica de la estructura social sobre la que subyace, puesto que éste es un recurso del que disponen los actores sociales, en función de su ubicación en la estructura de sus relaciones sociales.

Para Bourdieu el capital social es "el conjunto de recursos actuales o potenciales que están vinculados a la posesión de una red duradera de relaciones más o menos institucionalizadas de conocimiento y reconocimiento mutuo" (1985: 248, citado en Portes 1999). En La distinción Bourdieu nos ofrece una explicación más completa del concepto de capital social cuando afirma que es

\footnotetext{
una relación social [...] una energía social que ni existe ni produce sus efectos si no es en el campo en el que se produce y reproduce, cada una de las propiedades agregadas a la clase recibe su valor y su eficacia de las leyes específicas de cada campo: en la práctica [...] en un campo particular todas las propiedades incorporadas u objetivadas vinculadas a los agentes no siempre son simultáneamente eficientes; la lógica especifica de cada campo determina aquéllas que tienen valor en ese mercado, que son pertinentes y eficientes en el juego considerado, qué, en relación con ese campo, funcionan como capital específico, y en consecuencia, como factor explicativo de las prácticas (1988: 112).
}

Es decir, el capital social no existe como tal, solamente existe en la medida en que produce efectos para el agente que lo pone en práctica en un campo específico. Esto significa que quien lo pone en práctica conoce 
la lógica del campo en el que está operando y tiene conocimientos sobre cuáles son las acciones pertinentes que debe emplear. Es decir, el agente tiene el poder para determinar qué tipo de prácticas se van a ver traducidas en un capital específico y que, además, le permiten explicar por qué razón pone en acción un tipo de prácticas y no otras (Portes, 1999). Más adelante vuelvo sobre las prácticas.

El tratamiento que Bourdieu le dio al concepto capital social, de acuerdo con Portes y Landolt (2000), fue instrumental en el sentido de que el agente de manera deliberada construye sus relaciones para obtener un beneficio para él o su familia, lo que se deriva del o los vínculos que éste tiene con los demás. Bourdieu distingue entre capital económico, capital social y capital cultural y será a través del segundo que los agentes logren acceder a una diversidad de recursos económicos al tiempo que incrementan su capital cultural en razón del contacto que tienen con la experiencia de otros individuos. Por esto el capital social se relaciona con la capacidad de los agentes para lograr beneficios, y éstos se logran mediante su pertenencia a redes sociales, así como a otras estructuras sociales (Portes, 1999). Así, a partir del concepto de capital social es posible explorar las diferentes formas en que la organización de la estructura afecta la acción económica. Aunque se debe tener en cuenta que para poder adquirir capital social se requieren inversiones de recursos económicos y culturales de manera deliberada. Ahora bien, para Bourdieu las tres formas de capital son fungibles, es decir, son intercambiables unos por otros, aunque reduce todas las formas al capital económico que define como trabajo humano acumulado. Respecto del capital cultural, se define a partir de las credenciales educativas formales que un individuo posee, junto con un intangible complejo de valores y estilos de comportamiento.

El habitus necesariamente vinculado al concepto de capital contribuye a explicar, con mayor profundidad, dónde parecen originarse las diferencias entre los agentes, en este caso los empresarios, y cómo sus prácticas contribuyen o no a la adquisición de capital social. El habitus "es ese principio generador y unificador que retraduce las características intrínsecas y relacionales de una posición en un estilo de vida unitario, es decir, un conjunto unitario de elección de personas, de bienes y de prácticas" (Bourdieu, 1997: 19). El habitus es un principio diferenciador y diferenciante que se expresa en lo que el individuo hace diferente con respecto a los otros pero, sobre todo, la manera como lo hace, esto es, cómo imprime un sello que lo distingue de los otros, pero que lo integra con sus homólogos. Es esta forma de hacerlo lo que genera prácticas que son distintas y distintivas, en relación con otros, donde se hacen evidentes las diferencias. Al mismo tiempo, este habitus es clasificatorio de la visión del mundo, esto es, cómo lo simboliza, percibe, define, estructura, 
y lo mismo sucede para conceptos como familia o aficiones. Son estos sentidos distintivos en relación con otros grupos lo que produce también prácticas distintivas, pero compartidas en un espacio social de homólogos (Bourdieu, 1997: 22). Para Bourdieu estos principios funcionan en cada sociedad donde el espacio social estructura posiciones diferenciadas pero definidas "por el lugar que éstas tienen en la distribución de una especie particular de capital”. El espacio social agrupa a los agentes homogéneos desde el punto de vista de sus condiciones de existencia y de sus prácticas culturales, de sus consumos, etc. (Bourdieu, 1997: 22). Es decir, el habitus se traduce en prácticas constantes acerca de lo que se debe hacer en situaciones determinadas donde juega la visión y la percepción que el sujeto y el grupo tienen respecto de qué se debe hacer, cómo se hace y quién lo hará en cada caso. Esto es relevante ya que contribuye a comprender algunas acciones que tienen lugar en el microespacio de las decisiones individuales, en este caso de los empresarios, donde estas prácticas de clase, y por ende cómo se responde, se combinan con el contexto macro de la estructura, de oportunidades, y produce también acciones diferentes en los distintos actores económicos.

\subsection{Las empresas familiares}

Las empresas de tamaño micro y pequeñas son la forma más extendida de unidades económicas en México y tienen en común que son empresas familiares. Estas unidades económicas iniciaron operaciones sobre la base de una inversión inicial que, muchas de las veces, provino de ahorros familiares o bien una combinación entre ahorros y un salario que apoyó su desarrollo durante algún tiempo (Serna, 2003). Al iniciar actividades contaron con un número reducido de trabajadores, algunos de los cuales son miembros del grupo familiar e incluso, por algún tiempo, quizá no recibieron un salario por el trabajo realizado. Estas características contribuyen a explicar por qué fácilmente se multiplican en número y también por qué pueden desparecer con la misma facilidad con que surgieron. Otras en cambio, en el mediano plazo, logran incrementar sus inversiones, así como su número de trabajadores y se desarrollan hasta consolidarse. $\mathrm{Al}$ mantenerse en operación durante varias décadas, estas empresas se han visto afectadas de diversas maneras por los ajustes estructurales, al igual que por las crisis económicas que han impactado las regiones donde éstas se ubican.

En términos de definición por tamaño, a partir de 1985 surgieron diversas definiciones y clasificaciones sobre lo que se debía considerar como empresas de tamaño micro y pequeñas. No me ocupo de las discusiones previas que esta forma de agrupamiento suscitó, sino que centro 
mi atención en las dos modificaciones realizadas por la Secretaría de Comercio y Fomento Industrial (Secofi), actualmente Secretaría de Economía, y que fueron publicadas en el Diario Oficial de la Federación en 1985 y 1993, respectivamente (cuadro 1).

\section{Cuadro 1}

\section{Clasificación de las empresas en México, 1985 y 1993}

\begin{tabular}{|c|c|c|c|c|}
\hline & \multicolumn{2}{|c|}{ Microempresas } & \multicolumn{2}{|c|}{ Pequeñas empresas } \\
\hline & Personal & Ventas & Personal & Ventas \\
\hline il de 1985 & De 1 a 15 & $\begin{array}{l}\text { Hasta } 30 \text { millo- } \\
\text { nes de pesos }\end{array}$ & Entre 16 y 100 & $\begin{array}{l}\text { Hasta } 400 \text { millones } \\
\text { de pesos }\end{array}$ \\
\hline $\begin{array}{l}3 \text { de diciembre } \\
\text { de } 1993\end{array}$ & De 1 a 15 & $\begin{array}{l}\text { Hasta } 900,000 \\
\text { pesos }\end{array}$ & Entre 16 y 100 & $\begin{array}{l}\text { Hasta nueve } \\
\text { millones de pesos }\end{array}$ \\
\hline
\end{tabular}

Fuente: Diario Oficial de la Federación.

Como se observa en el cuadro 1, en 1985 y 1993 se clasificó como microempresas a unidades que contaban con entre uno y 15 trabajadores. Para 1985 las ventas anuales de este grupo podían ascender hasta 30 millones de pesos, pero esto se modificó en 1993 después de la devaluación del peso hasta 900 mil pesos. En tanto que las pequeñas empresas serían las que tuvieran entre 16 y 100 trabajadores, aunque para 1985 se consideró que sus ventas anuales podían ascender hasta los 400 millones de pesos, monto que se modificó a nueve millones de pesos en 1993. Las empresas a que este análisis se refiere se ubicaban en alguna de las dos categorías, y todas tenían en común ser empresas familiares.

\section{La actividad empresarial en México en las últimas dos décadas del siglo $\mathrm{XX}$}

Los sucesos económicos de las últimas dos décadas del siglo xx en México tuvieron efectos muy diversos en el ambiente en que las pequeñas empresas familiares se habían desarrollado. A principios de los ochenta, el modelo de sustitución de importaciones caracterizado por una importante protección comercial y una intensa intervención gubernamental (Martínez, 1995: 26) había llegado a su fin. Se resintió la caída de los precios internacionales del petróleo, así como un aumento en las tasas de interés internacionales. Estos factores desencadenaron una crisis que estalló en 1982 y llevó a la moratoria del pago de la deuda externa (Cortés, 1998: 3) al igual que a la fuga de capitales, ante la frágil situación económica, lo que revirtió las tendencias del crecimiento económico. Ante estos eventos, se puso en marcha una serie de severas medidas de política económica y reformas estructurales que dieron forma a una nueva estra- 
tegia de desarrollo económico. Las políticas de la primera mitad de los ochenta se orientaron a la estabilización y ajuste de la economía e hicieron hincapié en la reducción del déficit fiscal, así como en la promoción de las exportaciones.

Se registró una fuerte restricción de créditos que produjo escasez de financiamiento para el sector privado, combinado con altas tasas de interés. En el aspecto cambiario, el peso se mantuvo subvaluado hasta 1987 y se priorizaron las medidas antiinflacionarias que llevaron a una sobrevaluación del peso frente al dólar, que se hizo evidente a principios de 1990. En los años que siguieron se establecieron diversas medidas organizadas en torno al Pacto para la Estabilidad Económica (Martínez, 1995: 29), que logró reducir la inflación a un dígito en 1994, aunque ya la economía había empezado a perder dinamismo (Cortés, 1998: 7). A fines de 1994, ya con el Tratado de Libre Comercio de América del Norte (TLCAN) en marcha, México enfrentó otra devaluación y con ello una nueva alza inflacionaria.

Respecto a la política comercial, entre 1982 y 1992 la protección arancelaria se redujo al máximo, la liberalización comercial se aceleró y las importaciones registraron de nuevo un incremento importante. Este proceso de apertura comercial incluyó también el desmantelamiento de la política industrial y la eliminación de incentivos fiscales, entre otros estímulos (Martínez, 1995). Como consecuencia de estas acciones las empresas familiares sufrieron el rigor de las reformas estructurales y la severa crisis económica. Entre 1982 y 1987 la economía mexicana se estancó y como efecto las empresas enfrentaron el racionamiento de créditos y un alza en las tasas de interés. A diferencia de las grandes firmas, las empresas familiares tuvieron severos problemas para obtener financiamiento. Entre 1988 y 1993 se desarmó la protección a las empresas y comenzó un proceso de reevaluación cambiaria, la apertura externa se aceleró y provocó que las exportaciones crecieran por encima de la economía en su conjunto (Martínez, 1995: 31-34). Estos factores desencadenaron la urgencia de iniciar un proceso de modernización de los procesos productivos que fue encabezado por la gran empresa de origen nacional, así como por las grandes empresas transnacionales. Sin embargo, para las empresas familiares, especialmente de la industria manufacturera, llevar a cabo un proceso acelerado de reestructuración resultó muy difícil, pues además estaban enfrentando la entrada de mercancías de importación a precios competitivos. Así, al tiempo que se daba la apertura comercial, se dejaba de atender la estrategia de industrialización basada en un sistema de protección de la competencia externa y de asignación de estímulos fiscales. Por ello los nuevos programas sectoriales se enfocaron en promover la competencia y la internacionalización de los productos (Martínez, 1995). 
Al dejar al libre mercado la determinación del perfil de la producción industrial, se intensificó el proceso de reestructuración industrial y provocó que los esfuerzos exportadores se concentraran en unas cuantas ramas y empresas, así como que algunos fabricantes se reconvirtieran en importadores, que se incursionara en la economía subterránea, o bien se diera la quiebra de empresas como una forma de depurar la planta manufacturera. Como se carecía de una política industrial de largo plazo, se ofrecieron apoyos para atenuar la crisis por la que atravesaban las empresas (Martínez, 1995: 40). En 1996, a unos meses de anunciado el Programa Nacional de la Micro, Pequeńa y Mediana Empresa, cuyo objetivo era apoyar a la planta industrial en materia de desregulación y simplificación administrativa, la Cámara Nacional de la Industria de la Transformación (Canacintra) estimaba que se había registrado una disminución de 50\% de empresas y empresarios como consecuencia de la macropolítica llevada a cabo, y tenía razones fundadas para ello.

Como un efecto de los cambios, reestructuraciones y crisis económicas la población económicamente activa (PEA) en actividades empresariales sufrió un severo decremento entre 1970 y 1990: de 6.60 a 2.29\%. Es decir, se registró una reducción de casi cinco puntos porcentuales en ese lapso (Serna, 2003: 93), lo que representó un severo impacto económico para el país. Para el año 2000 la PEA empresarial registró un ligero incremento y representó $2.53 \%$ del total (Serna, 2002: 5), aumento mínimo al que pueden haber contribuido los programas de apoyo y fomento a las empresas. Sin embargo, no se logró alcanzar el porcentaje que se tenía tres décadas atrás.

Estos acontecimientos nacionales se reflejaron en los distintos estados y municipios del país con efectos muy diversos. En Aguascalientes, en los últimos 20 años del siglo xx también se dio un proceso de reestructuración productiva que consistió básicamente en que el estado pasó de ser una economía que descansaba sobre todo en las actividades agropecuarias y comerciales, a otra cuyos ejes básicos de crecimiento fueron las manufacturas y los servicios. Este proceso de industrialización se concentró en la ciudad capital, donde se concentraba cerca de $75 \%$ de su población y la mayor cantidad de empresas, lo que significó un cambio hacia una economía fundamentalmente urbana que amplió la influencia del estado en el ámbito regional (Implan, 2004).

En este contexto se generaron y aprovecharon las condiciones que se tenían para posicionar a la ciudad de Aguascalientes como un centro industrial integrado por empresas vinculadas al mercado nacional y al internacional (Salmerón, 1996). No obstante, en términos de eficiencia económica el desempeño de los distintos sectores fue muy desigual. Mientras que las manufacturas tuvieron un crecimiento equilibrado y fue 
claro el incremento en su productividad, el comercio y los servicios tuvieron un retroceso generalizado puesto que su crecimiento no fue muy eficiente y tampoco se aumentó su productividad como se esperaba. Esto se reflejó en una constante reducción de las remuneraciones por persona, por lo que para finales del siglo xx la economía de la ciudad empezó a tener claros síntomas de recesión (Implan, 2004).

Con respecto a la PEA empresarial en Aguascalientes, como consecuencia de los cambios y proceso de reestructuración sucedió algo similar a lo registrado en el ámbito nacional. Así, entre 1970 y 1990 se registró un severo decremento de la PEA empresarial que pasó de 10.2 a 3\%, lo que significó una reducción de siete puntos porcentuales, muy superior a la registrada en el contexto nacional. En el año 2000 representó 3.15\%, es decir, un incremento incluso menor al registrado en el país. Esto puede significar que la crisis económica de 1995 fue más severa en Aguascalientes, y que en razón de esto los programas apenas paliaron mínimamente sus efectos en el sector empresarial. Por supuesto la proporción porcentual de la PEA empresarial se mantuvo muy alejada de la que se tenía en 1970, además de que había signos evidentes de recesión a pesar de los apoyos económicos promovidos.

\section{Un proceso de construcción de redes que logran capitalizarse}

En esta sección analizo la forma en que se gestaron y desarrollaron dos empresas familiares: una de tamaño micro y otra pequeña, ambas manufactureras, y cómo los actores económicos enfrentaron la contracción económica de 1985 y 1995 . Hago énfasis en la forma en que los empresarios establecieron relaciones y tejieron un entramado de redes de apoyo que les permitió sortear las dificultades económicas. Para dar cuenta del proceso, llevo a cabo un análisis de la trayectoria de estas unidades económicas con el propósito de observar cómo los actores económicos entrelazaban las oportunidades que se les presentaban. También se destacan las diferencias respecto a la forma en que ambas accedieron a sus redes de relaciones, así como las ventajas y limitaciones que esto tuvo para los casos analizados.

Empresa 1. Esta microempresa tenía 18 años de antigüedad ${ }^{3}-y$ nueve registrada formalmente-, se dedicaba a la fabricación de artículos de carnaza (guantes para uso industrial) y contaba con 10 trabajadores: seis de planta, uno de los cuales era su cónyuge, cuatro de medio tiempo y dos maquiladores. Su propietario y responsable tenía 40 años de edad y 19 de

${ }^{3}$ El año de referencia es 1999 . Este propietario, al igual que los otros en este texto, fecha la antigüedad de su empresa desde que inició de manera informal: en el ańo 1981 y se formalizó en 1990. 
casado, tenía tres hijas de entre 14 y ocho años. Era originario de un poblado en Zacatecas y su familia había emigrado a Aguascalientes cuando él era pequeño, para que recibiera atención médica ${ }^{4}$ en el Instituto Nacional de Protección a la Infancia (INPI), donde también cursó su educación básica. Realizó estudios de secundaria y nivel técnico graduándose en administración de personal, era el único hijo de una numerosa familia que obtuvo un título.

Su ingreso al mundo laboral, como trabajador de medio tiempo, inició cuando tenía 13 años en una fábrica de guantes, pues los recursos de la familia eran escasos, ${ }^{5}$ por lo que combinó sus estudios con el aprendizaje del oficio de guantero. Al graduarse de técnico ingresó como trabajador de tiempo completo, no obtuvo un ascenso en la fábrica, a pesar de sus nuevos conocimientos, pero como tenía dificultades de movilidad decidió quedarse, pues consideraba que era difícil que alguien más lo contratara. ${ }^{6}$ Como tenía la certeza de que su salario no mejoraría, empezó a madurar la idea de emplearse a sí mismo y comenzó a ahorrar.

En poco tiempo empezó a fabricar productos propios, mientras continuaba como asalariado. Al principio cortaba sus piezas a mano y las enviaba a coser, pues no contaba con las herramientas necesarias, una vez terminadas, el fin de semana recorría las tiendas de la localidad para ofrecer sus productos. En esa época se casó y por falta de recursos se quedó a vivir en la casa paterna. Su esposa trabajaba como empleada en una tienda, pero su salario era muy bajo, ya que sólo había concluido la educación primaria. El primer préstamo para compra de materia prima al mayoreo, que saldó muy rápidamente, provino de su suegro, "quién vio que tenía ganas de trabajar". Sin embargo, su desconocimiento respecto de quiénes eran y cómo operaban los proveedores de mayoreo ${ }^{7}$ le ocasionó sorpresas, como darse cuenta de que los que contactaban proveedores cobraban por realizar la intermediación. Como sus recursos eran escasos optó por invertir en un contacto y confiar en su habilidad para establecer sus propias redes y conocer a otros proveedores. En corto tiempo logró establecer relaciones de confianza con otros proveedores, como el pago contra entrega de un pedido a otro. La fábrica en que trabajaba renovó su maquinaria y compró de oportunidad una cosedora con la intención de incrementar su producción. Su patrón lo despidió cuando se dio cuenta "de su pretensión de ser guantero", con la excusa de que no cumplía con las tareas que se le

${ }^{4} \mathrm{Al}$ poco tiempo de nacer contrajo poliomielitis.

${ }^{5} \mathrm{Su}$ padre era empleado en una dependencia de gobierno y por esta razón tuvo acceso a los apoyos necesarios para que su hijo fuera atendido.

${ }^{6}$ El patrón tampoco le propuso mejores condiciones de trabajo o algún puesto diferente donde sacara ventaja de los conocimientos aprendidos en la escuela técnica.

${ }^{7}$ Las curtidurías estaban en León, Gto., en esa época a unas dos horas de Aguascalientes. 
asignaban. Aun cuando no estaba de acuerdo con su patrón, prefirió no entrar en conflicto y renunció al único empleo que había tenido.

Se dedicó entonces a la fabricación de guantes por cuenta propia, y rápido se dio cuenta que sus ingresos semanales eran apenas similares al sueldo que recibía, y además ya no contaba con las prestaciones de ley. Para abonar a su difícil situación, su padre insistió en que él y su familia se mudaran con su taller a otra parte, e incluso le regaló un pequeño lote en un poblado cercano a Aguascalientes para que ahí construyera su casa. Pero él tenía claro que si quería tener su taller este debía estar dentro del perímetro de la ciudad. A sabiendas de que los conflictos seguirían, vendió el terreno y continuó en la casa paterna. Invirtió el dinero en una cortadora y las herramientas necesarias para tener un taller equipado para fabricar guantes de carnaza. Contrató tres trabajadores y su esposa le ofreció apoyarlo y aprender el proceso para responsabilizarse del taller, además del cuidado del hogar, pues en ese periodo aún no tenían hijos. Esto marcó el inicio del taller todavía en la informalidad.

Su cónyuge aprendió en parte a organizar el trabajo del pequeño taller, lo que le permitió viajar en busca de compradores de mayor envergadura y resolvió el problema de contactar clientes de mayoreo pues obtuvo direcciones en las empresas de paquetería, mediante observación en donde siguió la misma lógica que para sus proveedores, "con uno o dos que conociera para empezar". Sin duda él contaba con el capital cultural para desarrollar una actividad independiente, por sus estudios sobre administración y trato con el personal, aunque al mismo tiempo enfrentaba limitaciones en términos de relaciones sociales, saberes y prácticas que su grupo de pertenencia le imponía. Debido a que la salida natural para su familia de origen era mantenerse como asalariado, su única red de apoyo era su familia política. Él había entretejido una serie de elementos que le garantizaran un cierto éxito y además conocía el proceso, la calidad de los materiales y del terminado. También buscó ingresar a las organizaciones de sus similares, pero no tuvo éxito. A pesar de los múltiples obstáculos, articuló adecuadamente sus conocimientos teóricos y prácticos, sacó ventaja de ellos y aprovechó al máximo los recursos económicos con que lo apoyó su familia política.

Aunque le fue difícil, pues no tenía conocidos en esa actividad, logró contactar algunos clientes en la ciudad de México con acuerdos que le permitieron disponer de recursos para elaborar sus productos. El acuerdo que logró y mantuvo como premisa fue recibir un adelanto de $50 \%$ al solicitar la mercancía y el resto a pagarse contra entrega, en un plazo no mayor de 15 días. Es probable que su propia presencia y empuje para movilizarse, a pesar de sus dificultades, le hayan sido de gran ayuda, aunque tenía claro que sus productos eran de calidad y precio competi- 
tivo. Durante algún tiempo se dedicó a cumplir sus entregas hasta que recibió la oferta de convertirse en maquilador. La idea de producir sin preocuparse de otras cosas le pareció buena y aceptó. $\mathrm{Al}$ reflexionar sobre esto consideró que, por desconocimiento de su parte, los acuerdos a que llegó no fueron buenos, pues no incluyó el desgaste y reemplazo de maquinaria. Durante cinco años maquiló, pero mantuvo a sus clientes minoristas en Aguascalientes. Las ganancias eran aceptables y sus pagos se hicieron en tiempo. En este periodo contrató más trabajadores, mejoró calidad, se dio espacio para analizar otros mercados y compró más maquinaria. También adquirió un terreno en una de las zonas de urbanización de bajo costo de la ciudad, con la idea de construir su casa y su taller y se mudó a una casa rentada, instaló su taller y así puso fin a los conflictos con su familia de origen.

Sus años como maquilador coincidieron con la crisis económica de mediados de los ochenta, que no tuvo efectos negativos en su empresa, y fue una fase en la que creció, ahorró e invirtió. Esto le generó un ambiente de confianza que resultó en beneficios para su proyecto económico, aunque al recapitular sobre ese periodo recordaba algunos inconvenientes: los pagos empezaron a demorarse, el volumen de producción disminuyó y no lograba incrementar el precio de sus artículos. Sin embargo, para él no fue tan claro lo que sucedió, pues su contratante fue quien resintió los efectos de esa crisis. Así, la decisión de maquilar resultó la más adecuada incluso con los problemas que tuvo, pues su pequeño taller fue cobijado por una entidad mayor, justo cuando hubo más dificultades y decidió no maquilar más, la etapa más severa parecía haber pasado.

$\mathrm{Al}$ reintegrarse a su papel de empresario contactó nuevos clientes en Monterrey, San Luis Potosí y ciudad de México, pues ya conocía su mercado. Reactivó sus relaciones con los proveedores y entonces la responsabilidad de la producción descansó en su cónyuge, a quién le resultaba difícil organizar a los trabajadores - pues su número había crecido-, planificar la entrega de pedidos y atender su hogar e hijos. Esto no era extraño, pues a pesar del esfuerzo carecía de los conocimientos para hacerlo ${ }^{8}$ y las cuestiones de manejo de personal y distribución del trabajo evidentes para el empresario, eran desconocidas para su cónyuge. Llama la atención que él no considerara necesario contratar a una persona calificada para hacerse cargo del área de producción. Es probable que para él no fuera evidente ${ }^{9}$ la diferencia de conocimientos y habilidades entre él y su esposa,

\footnotetext{
${ }^{8}$ Esto si dejamos de lado el hecho de que por ser mujer, en un ámbito de trabajadores varones, es muy probable que enfrentara cotidianamente la negativa de éstos a obedecer a lo que ordenaba la responsable. También para estas situaciones se requieren aprendizajes específicos.

${ }^{9}$ De hecho seguía sin ser evidente esta diferencia a finales de 1999 , por lo que tampoco había hecho nada para incorporar personal calificado y no depender de la familia inmediata.
} 
lo que puede significar que no le asignara un valor preponderante a lo que había aprendido. ${ }^{10}$ Esta incomprensión de la diferencia entre ambos puede haber generado un desequilibrio que se tornó en obstáculo para avanzar en su proceso de crecimiento y consolidación, así como para enfrentar con mejores posibilidades los nuevos avatares económicos.

El periodo de bonanza continuó cuando volvió a fabricar sus productos, aunque le representó una carga de trabajo excesiva ya que se convirtió, como muchos microempresarios, en un hombre orquesta. Se hizo cargo de las compras, la distribución del trabajo y la comercialización y le facilitó el trabajo a su cónyuge. Fue entonces cuando formalizó su empresa y contrató un contador para elaborar facturas, pagos, etc. En 1993 contaba con una camioneta para el envío de pedidos y visitas a proveedores, mantuvo su capacidad de ahorro y no endeudamiento, volvió a mejorar parte de su maquinaria y contrató más empleados.

Orientó su actividad a reforzar sus relaciones con los proveedores, hizo más sólidas sus redes de confianza y se ocupó de que "sus clientes no prolongaran sus pagos". Esta constante actividad y movilización para atender el negocio, los proveedores, los clientes y su familia al cabo de algún tiempo acabó por ser insostenible. Mantener el capital social que había logrado acumular dependía exclusivamente de un sujeto: el empresario. Por otro lado, acorde con su grupo familiar de pertenencia, este apoyo debía provenir de la familia inmediata: su cónyuge. Su esposa se responsabilizó de la buena marcha del hogar, el cuidado de las hijas y la atención a la empresa, en la medida de sus posibilidades, lo que de suyo era ya una doble jornada de trabajo. A esto se añadía el no tener información sobre cómo se esperaba que desempeñara su apoyo en la empresa familiar. Era evidente que no habían construido un círculo de relaciones externas de amistad con personas dedicadas a la actividad empresarial, en cambio sus relaciones con los empleados eran cercanas. Adicionalmente, las organizaciones de pares no aceptaban la llegada de nuevos miembros y menos aún intercambiar experiencias para mejorar como sector. El ambiente era poco amable, pues se pensaba que los nuevos miembros sólo querían "conocer sus secretos", ${ }^{11}$ mismos que no estaban interesados en compartir. Este evento cuestiona las posibles ventajas que puede tener un empresario al formar parte de organizaciones donde la membrecía se paga, pero que no apoyan a quien tiene un negocio y busca consolidarse. ${ }^{12}$

\footnotetext{
${ }^{10}$ No tenemos información acerca de lo que sucedió mientras él estudiaba la carrera de técnico, pues puede haber tenido problemas con la familia por su empeńo en obtener un título.

${ }^{11} \mathrm{Al}$ explorar si se había acercado a alguna organización, dijo que ésta no había sido la mejor opción, ya que no había logrado nada.

${ }^{12}$ Es fundamental realizar estudios a fondo de estas organizaciones para sectores específicos de actividad económica. Los resultados de estos análisis pueden ayudar a comprender por qué el por-
} 
El exceso de trabajo y responsabilidades lo sobrepasaron, pero en 1993 logró un buen acuerdo y regresó a la maquila, como su perspectiva era de un entorno estable inició la construcción de su taller y casa familiar separados. A fines de 1994 y durante 1995 las quejas de su cliente-proveedor fueron frecuentes e insistía en que disminuyera el precio de costo, y también dejó de pagar a tiempo, era evidente que los problemas de liquidez de su cliente-proveedor afectaban su negocio. Ante lo incierto del panorama aceptó la propuesta de cancelar el contrato y saldar cuentas, a diferencia de lo que pasó en los ochenta, en la crisis de los noventa sí se vio afectado su negocio a pesar de ser maquilador, lo que permite suponer que esta última fue de mayor envergadura. Contactó de nuevo a sus clientes de mayoreo y proveedores, pero sus clientes minoristas también tuvieron dificultades pues el volumen de compra era menor. Sin embargo, tuvo problemas para acomodar su producción también entre los mayoristas, pues la situación económica era muy inestable y encontró que no estaba preparado para enfrentarla y tampoco tenía a quién recurrir. La carencia de liquidez lo afectó y suspendió la construcción de su taller y su casa y despidió a dos trabajadores. Los pocos recursos de que disponía los destinó a la compra de materias primas y al pago de sus empleados. Encontró que sus proveedores se negaron a concederle los plazos habituales y al mismo tiempo los clientes promovieron la ampliación de su crédito, y otros dejaron de pagar sus adeudos, lo que lo obligó a reducir su personal, al menos temporalmente.

Era innegable que su red de proveedores y sus clientes estaban volcados en resolver sus propias dificultades. Como su prioridad era el taller, la familia tuvo que reducir al máximo sus gastos y soportar el peso de la crisis, sus hijas mientras tanto siguieron en la escuela pública. Al recapitular sobre este periodo, consideró que fue el momento más difícil que enfrentó como empresario, pues las dificultades de liquidez lo condujeron, contra su propia creencia, a solicitar créditos directos a la banca, pero las elevadas tasas de interés le hicieron desistir, para fortuna de él y su negocio. Optó entonces por un préstamo de nuevo de su familia política, su única red de soporte moral y económico segura, pues requería de capital de trabajo. Le prestaron lo suficiente para reactivar su producción, poco después las ventas mejoraron y, con la anuencia de su cónyuge, mantuvo su postura de destinar todos los fondos a la empresa familiar. Al cabo del tiempo continuó la construcción de su taller y su casa. En 1998 logró liquidar sus deudas familiares, recontrató a sus antiguos trabajadores,

centaje de personas que pertenecen a alguna organización en México es tan reducido con respecto a otros países. Es muy probable que situaciones similares a la descrita sean nota común en estos grupos. 
concluyó la construcción de una pequeña nave industrial para su taller, así como la casa familiar.

La situación mejoró y en 1999 renovó parte de su taller, para lo que exploró varias opciones de financiamiento, distintas a la banca, que lo condujo a formar parte del grupo de empresarios apoyados por un programa para la microempresa en Aguascalientes, del que obtuvo 50,000 pesos a una tasa anual de $20 \%$, que desde su perspectiva era razonable. Su incorporación al programa incluyó también asesoría para la administración de su negocio, lo que resultó importante ya que le sugirieron cómo establecer sus líneas de producción, eliminar desperdicio y ordenar en general su taller que comenzó a lucir organizado y limpio. La preguntas son: ¿el apoyo que recibió en aspectos administrativos lograron generar los conocimientos respecto de la importancia de contar con redes sociales que le permitieran acumular un capital social y económico que lo ayudara en la siguiente crisis? y ¿las asesorías le permitieron darse cuenta de la importancia de contar con al menos una persona calificada para apoyarlo? Todo parece indicar que no fue así.

A finales de 1999 este empresario no había resuelto algunos de los problemas que lo preocupaban, ya que su intención era impulsar el crecimiento de su empresa, mejorar sus procesos y la calidad de sus productos. Seguía como hombre orquesta, responsable de la compra de materias primas, la producción, el manejo de personal y la comercialización, sin distribuir responsabilidades vía la contratación de personal calificado. Es decir, no había logrado modificar su perspectiva o desarrollar nuevas posturas respecto de la importancia de conseguir apoyos sociales externos. Esto parece aludir a una dificultad derivada de su grupo de pertenencia y asociada al tipo de prácticas que para su entorno eran las esperadas. Estamos entonces frente a un sujeto económico que puede reconocer las oportunidades que se le presentan, pero no cuenta con los conocimientos ni ha logrado acumular el capital cultural y social para tomar ventaja de ellas.

Resulta interesante su razonamiento sobre los motivos que tuvo para acudir a un programa de financiamiento promovido por el gobierno estatal; expresa el tipo de comprensión y conocimiento que se tiene sobre las funciones y responsabilidades que el aparato gubernamental tiene respecto de lo que es la puesta en marcha de una política económica. En palabras del empresario: "Cuando andábamos en la asociación de deportistas en sillas de ruedas, él (se refiere a Felipe González) nos dio muchos apoyos; y ahora que se presenta de gobernador... que se me viene a la mente: chance y me ayude. Y sí me ayudó, me prestaron...” En su razonamiento, alude a las características de un sujeto orientado a las acciones de tipo filantrópico - como apoyar a deportistas con problemas de motricidad-, que cuando se torna en cabeza del aparato gubernamental seguiría con este 
tipo de acciones caritativas. Claramente no hay una comprensión de que las entidades gubernamentales responsables de la política económica dejaron de cumplir con su obligación de apoyar en la crisis al sector empresarial, y que su respuesta fue particularmente tardía, puesto que estos apoyos no estuvieron disponibles durante la fase más aguda de la crisis.

En contraste con la empresa analizada, me ocupo ahora de una situación que muestra lo que sucede cuando las condiciones generales del entorno externo -de relaciones y apoyos-, así como el interno -de lo familiar-propician cambios enfocados a la consolidación de una unidad económica. En otras palabras, cuando se reconocen las oportunidades y se cuenta con los conocimientos para tomar ventaja de ellas. Los problemas a resolver se ubican entonces en el territorio de la sucesión, un tema conflictivo en las empresas familiares.

Empresa 2. Ésta es una empresa familiar pequeña de confección de blancos, con 23 años de antigüedad ${ }^{13}$ y 30 trabajadores, cinco en mandos medios, miembros del concejo de accionistas y familiares directos de la empresaria y promotora. Su propietaria y cabeza de la empresa tenía 55 años al momento de la entrevista, contaba con un título de enfermera, estaba casada con un técnico industrial y tenían cuatro hijos en edad adulta: tres mujeres y un hombre, todos con estudios universitarios ya concluidos o por terminar, en áreas relacionadas con la empresa. Se trata de un grupo familiar con una posición económica desahogada.

Esta empresaria trabajó varios años como enfermera en el sistema público de salud y en 1976 empezó también a fabricar blancos, pues sabía coser y bordar, por lo que compró una máquina y contrató a dos operarias. Este patrón de incursión en la industria de la confección y el bordado en Aguascalientes $^{14}$ era común, algunas mujeres tenían su maquiladora con una o dos trabajadoras y otras, como fue en el caso de estudio, ingresaban a la actividad empresarial de tiempo completo (Serna, 2003). Vendía sus productos ${ }^{15}$ a conocidos y compañeros de trabajo, lo que le permitió contar con ingresos adicionales. A principios de los ochenta tuvo problemas de salud y decidió jubilarse y dedicarse a la fabricación de blancos, pues ya contaba con clientes fijos. Como también era común en Aguascalientes, instaló su taller en el segundo piso de la casa familiar, lo que le permitió atender con menos complicaciones el hogar y los hijos. Como la casa se sostenía con el salario de su esposo como técnico en ferrocarriles, ella in-

\footnotetext{
${ }^{13}$ La empresaria fecha la antigüedad de su empresa a partir de que inició actividades de manera informal. Hay que recordar que la fecha de referencia en este texto es 1999.

${ }^{14}$ En las últimas tres décadas del siglo xx la industria del bordado, la confección y el vestido fue muy importante en Aguascalientes.

${ }^{15}$ La materia prima que se requería para el proceso se vendía en Aguascalientes, al igual que la maquinaria. Aunque también había toda una red de intermediarios que le ofrecían una variedad de telas puestas en el domicilio del empresario.
} 
virtió sus ahorros en la compra de maquinaria, materias primas y contrató más operarias. Esta estrategia de contar con un ingreso mensual seguro, al mismo tiempo que se intenta desarrollar una empresa, redunda en un apoyo importante a esta última (Serna, 2003), pues buena parte de los gastos descansan en el asalariado y las ganancias se reinvierten en el fortalecimiento de la empresa. También en ese periodo formalizó su empresa.

$\mathrm{Al}$ integrarse a la industria de la confección se registró ante la Cámara Nacional de la Industria del Vestido en Aguascalientes (Canaive), organización que se ocupa de apoyar y fortalecer a ese sector con reuniones fijas para analizar problemas, dar cursos, orientaciones, sugerencias, etc. También se dedicó a buscar nuevos clientes locales y estableció contacto con clientes de la región, a quienes les enviaba sus pedidos. Pronto solicitó un préstamo bancario, que pagó sin problema, compró materias primas al mayoreo y amplió el taller en otra sección de la casa familiar. En esta primera fase de la empresa su gestora contaba con los conocimientos y habilidades para dedicarse a la confección de blancos -considerada una actividad femenina-, aun cuando su desempeño profesional había sido en el sector salud. Como incursionó en una actividad muy extendida y dinámica, que había desarrollado una infraestructura de apoyo muy sólida, acceder a información sobre compra de materias primas y maquinaria resultaba relativamente fácil. Algunos materiales se fabricaban en la localidad e incluso había un mercado especializado de intermediarios, que proveía de materia prima puesta a domicilio con acuerdos similares a los que ella establecía con sus clientes: un crédito pagadero a 30 días. Probablemente por haber laborado en una institución en donde la participación sindical era importante, resultó parte de sus prácticas vincularse -al cambiar de actividad- a la organización que representaba los intereses de la industria a la que pertenecía. Conjuntaba así todos los elementos necesarios para contar con un buen capital de soporte para el desarrollo de su negocio y además recibió el apoyo de sus familiares, amistades y compañeros de trabajo para conseguir clientes.

Su siguiente paso fue invitar a su cónyuge a formar parte de la empresa: aceptó, se jubiló y se incorporó como responsable del área de ventas. Este paso fue decisivo para garantizar un fuerte empuje al proyecto, pues contaba con una persona de confianza, mientras ella se hizo cargo del taller y las operarias. ${ }^{16} \mathrm{Su}$ siguiente inversión importante fue un local en una plaza comercial promovida por los fabricantes y apoyada por el gobierno para la venta directa de fábrica a clientes mayoristas y minoristas, con lo que logró una buena difusión de su empresa y con ello clientes

${ }^{16}$ Véase Serna (2003), cuyos estudios reportan las ventajas que tiene para el hogar y la empresa que la unidad de producción y reproducción se enlacen. 
importantes. Estableció un nicho de mercado y un conjunto de relaciones que fueron un soporte para la consolidación de la empresa. A mediados de los ochenta las ventas al mayoreo disminuyeron, por lo que tuvo que despedir a algunas operarias. Como necesitaba recursos solicitó un préstamo a la Canaive, y en el hogar recortaron gastos sin descuidar la educación de sus hijos, que era una prioridad para ellos. Había cierta tranquilidad pues el hogar contaba con un ingreso constante -aunque de un monto menor- proveniente de la jubilación. Al recapitular sobre esta primera crisis consideró que los tiempos fueron difíciles, pues tuvieron que salir a buscar clientela a otras regiones del país, pues sus ventas se limitaban a algunos clientes de mayoreo, minoristas y clientes ocasionales. En términos de impacto de esta crisis no parece haber sido tan severa, pues productores del sector, que como ellos atendían el mercado nacional y no exportaban, reportaron menos dificultades que el resto de los empresarios en ese periodo.

A fines de los ochenta los volúmenes de venta se habían incrementado, se saldaron y contrajeron nuevas deudas, se contrataron nuevas operarias, un contador para la administración -pago de nómina, impuestos, etc., pues ninguno tenía experiencia contable-y una secretaria. Para entonces, como ha sido tradición en esa industria, ${ }^{17}$ los hijos habían iniciado el aprendizaje de la empresa, por lo que pasaban unas horas familiarizándose con los procesos, el trato a las trabajadoras y en la tienda con la clientela, y aprendiendo a vender sus productos. Esto ha formado parte de los saberes prácticos entre quienes se dedican a esta industria familiar que, curiosamente, pasa de madres a hijos (Serna, 2003). A principios de los noventa reorganizaron las áreas de producción y comercialización, terminaron una nave industrial en donde se instaló el taller para separarlo de la casa familiar. También hubo un cambio temporal en las áreas: el cónyuge se hizo cargo del taller, de organizar la producción y del manejo de personal; y la empresaria del área de compras y comercialización.

Poco tiempo después la empresa se reestructuró y convirtió en sociedad anónima, los hijos y el cónyuge fungieron como accionistas y la fundadora asumió el cargo de presidenta del concejo. En la nueva estructura la hija mayor se incorporó a la empresa a cargo de la administración general, contrató personal auxiliar contable para "poner en orden la contabilidad de la empresa”, organizó los inventarios de compra, la existencia de materias primas y producción, definió los lotes de los distintos productos, ${ }^{18}$ entre otras cosas, lo que no resultó una tarea fácil. El único varón asumió, en colaboración con su padre, la responsabilidad del taller

\footnotetext{
${ }^{17} \mathrm{Al}$ menos así ha sido en la ciudad de Aguascalientes (Serna, 2003).

${ }^{18}$ En este periodo la empresa ya ofrecía una gama de productos de blancos de distintas calidades, para una amplia variedad de clientes y mercados.
} 
y su operación, lo que no estuvo exento de problemas, aunque el hijo sí logró organizar las líneas de producción para facilitar la distribución de tareas. Otra de las hijas, que estudió mercadotecnia en León, Gto., y su madre se hicieron cargo del área de ventas, surtir pedidos y atender las dos tiendas, la de Aguascalientes y la de León, que se abrió cuando la hija estudiaba como una forma de poner en práctica sus conocimientos y ampliar el mercado. La hija menor, que estaba al final de su carrera de diseño, se hizo cargo del departamento de diseño y desarrollo de nuevos productos. Aunque formalmente en el organigrama había una nueva estructura, en la práctica se registraron algunas dificultades entre las generaciones, pues los padres mantuvieron el control de la empresa y a los hijos les llevó tiempo separar responsabilidades.

La incursión de la segunda generación atrajo en poco tiempo nueva clientela, sobre todo empresarios del sector turismo, pues una parte de la producción se enfocó en vestir hoteles con nuevos diseños y materiales. A pesar de todas estas innovaciones, a mediados de los noventa se dejaron sentir los primeros efectos de la crisis y las ventas disminuyeron, al tiempo que los clientes solicitaron la extensión de sus créditos, si bien los acuerdos con proveedores se mantuvieron sin cambio. Como respuesta a la crisis, las hijas hicieron propuestas innovadoras para atraer clientes. En un esfuerzo organizado por las empresas del mueble y otras asociaciones de empresarios, se promovieron exposiciones. En las grandes plazas comerciales de las zonas urbanas más importantes del país los fabricantes de enseres, muebles, artículos para el hogar y confecciones de todo tipo realizaron exposiciones-venta de sus productos. Dos de las hijas que habían establecido contacto con algunos fabricantes y con empresarios del sector turismo participaron activamente en la propuesta y la fundadora, para quien fue evidente que había problemas, optó por dejarlos actuar. En estas exposiciones-venta lograron pedidos importantes de sus líneas económica, de calidad intermedia y dieron a conocer sus líneas boutique, además de lograr nuevos contactos con promotores y clientes potenciales. $\mathrm{Al}$ recapitular, la hija y administradora consideró que fue un momento de aprendizaje muy importante, aun cuando hubo que trabajar arduamente y las ventas disminuyeron, para ella la evaluación general fue positiva. El recuento de la crisis, sin embargo, no fue igual para la fundadora, pues los clientes empezaron a no pagar sus deudas, por lo que tuvo que recurrir a demandas, pagar abogados, etc. En esa época exportaba ya a Centroamérica y en varias ocasiones los envíos se quedaron en los contenedores de la aduana, en espera del pago de facturas. Aun cuando la empresa no había contraído deudas, hubo que despedir operarias y 
las que quedaron no tuvieron incrementos salariales durante varios años, ${ }^{19}$ lo que significó que, en el largo plazo, el impacto de la crisis económica fuera menor para los propietarios que para los trabajadores.

Un aspecto que merece comentarse es el relativo a los esfuerzos de integración, entre empresarios de distintos sectores productivos, y que tuvo una vida activa de apenas tres años, lo que deja ver las dificultades para organizarse alrededor de un proyecto. En la última exposiciónventa del grupo las condiciones cambiaron y el fabricante asumió, de manera individual, los costos de instalación y exhibición, incluida la renta del espacio, lo que provocó que disminuyera la participación y se cancelara al año siguiente. La responsable del área de ventas realizó una evaluación de logros y concluyó que participar en este tipo de exposiciones era útil, pues conocía a nuevos clientes potenciales, organizaba redes y al final mejoraban sus ventas, por esta razón se involucró posteriormente en la Expo-regalo.

En 1999 habían recuperado mercados, recontratado trabajadores -sin mejorar sus condiciones salariales y escatimando prestaciones-, contaban con diseños exclusivos, orientados a mercados de ingresos elevados, aunque seguían con sus líneas económicas y medias. La fundadora y sus hijas mantuvieron una buena relación con las cámaras y organizaciones empresariales, pues para ellas era fundamental formar parte de un esfuerzo bien organizado que fortalecía directamente a la empresa al contar con redes de soporte, muy útiles en las fases de crisis. También obtuvieron importantes préstamos para renovar maquinaria especializada, con lo que esperaban disminuir el número de operarias. Esta segunda generación tenía claro que era muy importante para el negocio disminuir aún más los costos de producción, incluso si esto implicaba enviar a sus trabajadores al desempleo. Para ello todavía tenían algunos problemas que resolver, pues se preciaban de que sus líneas boutique para mercados de ingresos elevados habían sido diseñadas para ser artículos elaborados a mano. No habían resuelto sus problemas de exportación, especialmente el pago de facturas, sus clientes mayoristas ya realizaban pedidos importantes, aunque todavía tenían facturas por cobrar de sus clientes nacionales.

La trayectoria de esta empresa, que sin duda acumuló un capital social y económico importante, nos permite observar las complicaciones y el trabajo que implica para varias personas -ya que en este caso la empresaria y gestora siempre contó con apoyos de todo tipo- ir tejiendo redes

${ }^{19}$ Todavía a fines de 1999 las operarias y vendedoras, pues el personal eran sobre todo mujeres, recibían el salario mínimo y la hija encargada de la administración no veía motivo para que su salario se incrementara. Incluso las operarias de las prendas boutique que requerían de habilidades de costura y terminado especializado, también recibían salario mínimo. Esta segunda generación había aprendido que de las crisis se recupera lo positivo y que los costos de producción deben ser mínimos, de ahí que había que pagar salarios precarios a los trabajadores. 
que le serán necesarias en distintas fases del proceso de consolidación de un proyecto económico. Lo que contrasta con el primer caso expuesto, donde el propietario tenía pocas posibilidades de que su grupo le ayudara a tejer una red efectiva, ya que carecían de conocimientos para hacerlo. En tanto que en el caso de la empresaria rápidamente se conjuntaron saberes y aprendizajes, lo que le facilitó librar mejor los periodos de crisis y sacar ventaja de ellas.

\section{De las dificultades para construir redes de apoyo}

En esta sección analizo la forma en que se desarrollaron dos empresas familiares: una microempresa y otra pequeña en el sector de las manufacturas. Elegí estos dos casos, como un contraste de los expuestos en el apartado anterior, donde las crisis de 1985 y 1995 las afectaron severamente. Se trata de empresas familiares que a pesar de sus múltiples intentos no han conseguido desarrollarse, sino que han transitado por quiebras frecuentes, donde de manera sistemática se reproducen errores, sin lograr aprendizajes. Sus gestores parecen no haber contado con los conocimientos necesarios para impulsarlas, no pudieron tejer redes de apoyo, y tampoco acumular un capital social o económico, por lo que dependieron, casi de manera exclusiva, de los apoyos que su núcleo familiar les proporcionaba.

Empresa 3. Esta pequeña empresa familiar se dedicaba a la fabricación de artículos de carnaza -guantes industriales-, tenía 19 años de haber iniciado formalmente actividades ${ }^{20}$ y contaba con 20 trabajadores: siete miembros de la familia, dos parientes políticos y el resto trabajadores de tiempo completo y medio tiempo. Su propietario tenía 44 años y 18 años cuando se casó, tenía seis hijos adultos: cuatro mujeres y dos hombres. El taller estaba instalado en un área de la casa familiar. El propietario provenía de una familia dedicada a la industria de la tortillería donde la práctica común era integrar a los hijos al negocio, por lo que cuando concluyó su educación primaria ingresó como trabajador y no continuó sus estudios. Trabajó en las tortillerías de la familia durante varios años hasta que se casó y su padre lo independizó y le regaló su propia tortillería.

Algunos años se dedicó a este negocio, mantuvo a su familia y compró una pequeña casa. Pero él no se interesaba en ese negocio y tampoco tenía una idea clara respecto del tipo de actividad que quería realizar. Uno de sus parientes, propietario de un taller de artículos de carnaza en la ciudad de México, lo convenció de que la producción de guantes era un buen negocio, y le ofreció enseñarle el oficio y comprarle su producción. Le interesó la propuesta y sin mucho meditar vendió la tortillería y la casa,

\footnotetext{
${ }^{20} \mathrm{El}$ ańo de referencia es 1999 . Su propietario formalizó la empresa al iniciar operaciones.
} 
por lo que la familia se mudó a una casa rentada. Fue así como se inició en la producción de guantes, sin tener conocimiento del oficio, en un mercado con múltiples ofertantes y con una mínima infraestructura de apoyo. ${ }^{21} \mathrm{~A}$ diferencia de los casos anteriores, él registró su empresa al iniciar operaciones, acorde con la práctica seguida por su padre en la industria de la tortillería. Sin embargo, contrario a lo prometido por su pariente, solamente recibió de él folletos y algunas especificaciones sobre tipo de maquinaria, así como direcciones de proveedores para la compra de materia prima.

Guiado por las sugerencias recibidas, compró la maquinaria y la materia prima y ocupó un espacio de la casa familiar en el que improvisó un pequeño taller. Averiguó por su cuenta dónde conseguir operarios con experiencia en corte, cosido, volteado y terminado y los contrató para iniciar operaciones. Arrancó su taller con una dependencia total de los trabajadores, por lo que pronto tuvo dificultades al no poder opinar sobre la calidad del trabajo. Su única opción frente a esta situación fue convertirse en aprendiz del oficio, asesorado por sus propios trabajadores quienes le enseñaron a elaborar el producto que él vendía. Empezó a enviar su producción a sus parientes, al principio no hubo problema y los pagos se hacían con prontitud, pero esto duró poco pues empezaron a dejar de pagarle completo y a prolongar los tiempos de pago, hasta que las deudas se acumularon. Hubo conflictos familiares, dejó de enviarles mercancía y optó por confiar en que en algún momento le pagarían los adeudos, aunque los problemas derivaron en retrasos a sus proveedores pues su capital de trabajó empezó a mermar.

Estas circunstancias lo obligaron a buscar nuevos clientes en Aguascalientes, un mercado particularmente competido, cuando al fin logró algunos, éstos empezaron a no querer pagar el precio de sus productos con el argumento de que la calidad de los terminados era muy variable. Aunque le resultaba difícil de aceptar, pues sus trabajadores decían que no era así, platicó con ellos y logró acuerdos para mejorar la calidad de los terminados, pues era lo más conveniente para todas las partes, él vendía los productos y ellos recibían su salario. Aun cuando mejoró la calidad de sus productos, la experiencia con sus clientes no fue buena pues nunca logró establecer contratos específicos de adelanto y pagos. Se quedó sin capital de trabajo, acudió a su grupo familiar y solicitó algunos préstamos hasta que las deudas le resultaron impagables. Así, a poco más de dos años de haber iniciado operaciones, cerró su negocio y se declaró en quiebra.

Como se puede observar en este caso, el inicio de una empresa es particularmente difícil cuando a esto se agrega un desconocimiento de

${ }^{21}$ Como ya se analizó para la empresa 1. 
los procesos de elaboración y mercados, ya que las posibilidades de fracaso se incrementan. En este caso se sumaron además otros problemas, pues él carecía de un capital cultural, en términos de aprendizajes escolares mínimos, para planear acciones a futuro. Es muy probable que esta práctica de improvisación fuera también algo que sus padres realizaban en sus negocios, pero esto lo hacían en un mercado radicalmente diferente y protegido. Él había hecho descansar el inicio de su negocio en relaciones de confianza con su familia extensa, lo que lo condujo directamente a perder no sólo sus posesiones materiales, sino la credibilidad y confianza para con sus proveedores y clientes.

Después de este fracaso migró a Estados Unidos para conseguir recursos, acabar de saldar sus deudas y enviar dinero a su cónyuge para sostener a su familia. Regresó con algunos ahorros y la intención de arrancar de nuevo su taller, pues ya conocía el oficio. Otra vez compró maquinaria, contrató trabajadores y decidió fabricar guantes industriales y cualquier artículo de carnaza que sus clientes solicitaran. Este segundo intento fue menos accidentado, aunque el esquema de clientes morosos continuó, por lo que a finales de 1985 enfrentó problemas de liquidez. Antes de que la crisis lo arrastrara por completo cerró su empresa y logró salvar parte de la maquinaria. Optó entonces por convertirse en maquilador, aunque no quedan claras las razones por las que tomó esta decisión. Este cambio de situación, como en el caso de la empresa 1, le permitió un periodo más largo de actividad constante y en la trayectoria de la empresa fue el ciclo más estable que tuvo, pues aparentemente logró un buen contrato que se prolongó durante varios años. En este lapso de maquilador consiguió reunir un pequeño capital, compró maquinaria y un terreno donde construyó la casa familiar e instaló el taller. Es decir, no se planteó como prioridad construir un espacio para el taller, como sí fue el caso de la empresa 1.

A principios de los noventa empezó a combinar su actividad de maquilador con la búsqueda de nuevos clientes, tanto en la región como en las ciudades de Guadalajara, y hacia el norte, en Monterrey y Tampico. Decidió reducir la producción para maquila, ya que estaba interesado en tener sus propios clientes con la idea de que sus ganancias serían mejores. Finalmente destinó su producción a sus nuevos clientes sin haber logrado contratos específicos de pago, es decir, permitió que la morosidad fuera, como había pasado antes, la relación más constante que mantenía con la clientela. En este proceso de altibajos su cónyuge no intervenía ya que él se mantuvo como jefe de familia y proveedor único. Los retrasos de pago por parte de su clientela fueron frecuentes y repitió los errores previos: mandaba los pedidos con la expectativa de que pagarían en algún momento. Como esto no sucedió, empezó a solicitar financiamiento y optó 
entonces por un préstamo bancario para tener capital de trabajo. Se endeudó de nueva cuenta y fue entonces cuando tuvo dificultades para combinar pago de salarios, de proveedores e intereses bancarios, pues éstos se fueron a la alza en proporciones inimaginables.

Para entonces la crisis de 1995 era evidente y el efecto que él recibió en su negocio fue devastador. Los gastos en el hogar se redujeron y sus hijos con la educación secundaria concluida trabajaban ya como empleados en algún negocio. Los problemas económicos se agudizaron y afectaron también su relación con proveedores al no pagarles a tiempo, por lo que la confianza que se había establecido se fracturó, situación que lo condujo finalmente a cerrar de nuevo el taller y declararse en quiebra. El panorama se tornó sombrío y tuvo que enfrentar una demanda que concluyó cuando probó que no tenía solvencia, lo que implicó no poder volver a solicitar créditos bancarios. Ante la necesidad de tener ingresos, durante casi dos años trabajó en lo que le fue posible y esto le permitió algunos ahorros. Los gastos en el hogar eran pocos pues sus hijos se habían casado y vivían aparte. A mediados de 1997 la idea de volver a tener su taller cobró forma y por primera vez recurrió a su cónyuge e hijos en busca de apoyo.

Entre sus ahorros y los de sus hijos reunió lo necesario para comprar parte de la maquinaria y materia prima. El taller arrancó con sus seis hijos y su esposa, pues llegaron al acuerdo de que eso sería lo mejor y la remuneración que empezaron a recibir era mínima, apenas para sostenerse y alimentarse, pues el propósito era "sacar adelante el negocio". Enfocaron la búsqueda en Monterrey y Tampico y lograron atraer clientes, compraron una camioneta para trasladar pedidos y materia prima. Sin embargo, a fines de 1998 empezaron los problemas de solvencia al repetir, una vez más, el mismo error de no hacer acuerdos de pagos contra entrega con sus clientes. Para 1999, al momento de la entrevista, ya contaban con algunos empleados de medio tiempo y otros de tiempo completo. Aunque como él mismo indicó, para entonces había recurrido a prestamistas de la localidad, que cobraban tasas de interés muy elevadas, pues requería pagar a proveedores y salarios.

Tres aspectos llaman la atención de esta última fase. Uno, que sus hijos e hijas, así como sus yernos estuvieran dispuestos a apoyarlo, a pesar de que su desempeño garantizaba que iría a una siguiente quiebra, pues el periodo de bonanza en esta pequeńa empresa fue muy corto. Otro aspecto interesante es que, aun cuando todos sus hijos participaron en este último arranque, ninguno parecía tener la opción de emitir alguna opinión respecto de los constantes errores cometidos por el responsable de la empresa. Lo que sin duda nos refiere a una figura de autoridad muy tradicional que se extendía hasta los cónyuges de las hijas, aspecto que 
quizá responda a que este tipo de práctica puede haber sido común en su grupo de pertenencia. Finalmente, que mantuviera una relación de excesiva familiaridad con sus trabajadores, pues él mismo explicaba que "aquí todos somos empleados, todos somos iguales". Desafortunadamente para la empresa, ésta era una actitud inadecuada, ya que implicaba que no había un responsable del proceso ni alguien que coordinara las actividades. Esto explica también que a pesar de sus múltiples intentos, no se haya registrado cambio alguno en la organización o algún tipo de especialización, sino que todos, incluido el propietario, hacían "lo que se necesitara para cumplir con los pedidos.

En la trayectoria de esta empresa podemos observar las dificultades que conlleva iniciar un proyecto económico sin contar con los conocimientos mínimos para hacerlo. El error que significa depositar la confianza en personas bajo el supuesto de que un grupo familiar se solidariza ante las necesidades, y que estas acciones pueden ampliarse hasta la familia extensa. También nos refiere a lo difícil que es regirse por preceptos de confianza que no son compartidos por todos aquellos con quienes se establecen relaciones, y cómo esto acaba por erigirse en obstáculos insalvables para el proyecto que se busca concretar. Además de los problemas que genera no poder acumular un capital social ni económico que redunde en beneficio del proyecto que se intenta llevar a cabo. A diferencia de los otros casos analizados, en éste encontramos a una persona sin un capital cultural para enfrentar los retos de un negocio, no hay un diseño de estrategias que coadyuven al desarrollo del taller, lo que lleva sistemáticamente a cometer errores sin lograr aprendizajes. Por último, en este caso, el propietario requería contar, por parte del aparato gubernamental, con apoyos múltiples, pero sus fracasos lo habían colocado fuera del sistema, lo que representa un severo problema ya que entonces no hay posibilidades de aprendizaje para quien tiene interés en desarrollar una empresa y carece de conocimientos mínimos. Como sucedió en este caso, una y otra vez se seguirá intentando, pero en una soledad total y contando solamente con la solidaridad de su familia inmediata, situación que no está exenta de rasgos de profunda ironía y contradicciones.

Empresa 4. Esta microempresa tenía cuatro años de estar en operaciones $^{22}$ y se dedicaba a la producción de artículos de cerámica de bajo costo. Contaba con seis empleados: dos de tiempo completo (su cónyuge y uno de sus hijos) y cuatro con contratos mensuales "sin compromiso con el patrón”. ${ }^{23}$ El taller estaba en un pequeño local y era atendido por cinco de los trabajadores, otro apoyaba a la propietaria que tenía una

\footnotetext{
${ }^{22} \mathrm{La}$ fecha de referencia es 1999. Esta empresa también se formalizó desde que inicio operaciones.

${ }^{23}$ De los casos expuestos es el único que tiene esta particularidad.
} 
tienda para la venta de sus artículos. Su propietaria tenía 54 años, 34 de casada y tres hijos con hogares ya formados e independientes, el grupo familiar había emigrado de la ciudad de México a Aguascalientes en 1982.

La situación actual de esta microempresa familiar es resultado de una serie de decisiones equivocadas tomadas por la pareja, que derivó en experiencias fallidas en los proyectos económicos que intentaron. Tres décadas atrás, viviendo aún en la ciudad de México, el cónyuge de la propietaria de la empresa de cerámica incursionó en los negocios y se dedicó a la compraventa de artículos de plástico. El negocio creció y les permitió comprar una casa y contar con un capital de trabajo. En este contexto uno de sus proveedores lo convenció de instalar su propia fábrica y además ofreció asesorarlo en todo lo relativo a la producción de artículos de plástico, lo que cumplió cabalmente. Compró una máquina de inyección, ${ }^{24}$ la materia prima que requería, consiguió un espacio para el taller, contrató algunos trabajadores e inició actividades. Tenía un buen conocimiento del mercado y pronto se familiarizó con los procesos y diseńó la cartera de productos que vendía en la tienda. A fines de los setenta contaba con un sólido negocio e incluso tenía clientes en varias zonas de la ciudad, por lo que su mercado era amplio.

En ese periodo fungió como responsable de su microempresa y la mantenía separada de la familia, por lo que cumplía con su papel de proveedor económico del hogar. Su esposa estaba a cargo del hogar y del cuidado de los hijos, y cuando se casó había dejado su empleo como recepcionista en un hospital. A principios de los ochenta sus hijos, adolescentes, empezaron a tener problemas y se involucraron en pandillas y situaciones más difíciles, lo que obligó a la familia a cambiar su lugar de residencia. Como tenían familia en Aguascalientes optaron por emigrar a esa ciudad.

No era fácil cerrar o trasladar la fábrica, por lo que vendieron su casa y compraron otra en la ciudad de Aguascalientes con una accesoria para que los hijos se dedicaran a la venta de plásticos y asumieran responsabilidades. El padre se quedó en la ciudad de México al frente de su fábrica, situación que se prolongó por algún tiempo, hasta que la esposa insistió en la necesidad de la presencia del padre en la casa familiar al menos unos días a la semana. El empresario optó por contratar a uno de sus hermanos como responsable de sus negocios y así dividir su semana entre Aguascalientes y la ciudad de México. Esta situación se mantuvo por algún tiempo, enseñó a sus hijos a vender en la tienda mientras estaba con ellos y viajaba a la ciudad de México a revisar cómo iban las cosas en la tienda y en la fábrica ${ }^{25}$ y regresaba de nuevo con su familia. La constante ausencia del

\footnotetext{
${ }^{24}$ Se trata de un tipo de maquinaria costosa.

${ }^{25}$ Hacer este tipo de viajes semanalmente implicaba unas siete horas de carretera para llegar de un lugar a otro, además de no poder dar seguimiento real a lo que sucedía en un lugar u otro.
} 
propietario en los negocios empezó a generar problemas con su hermano: los pedidos no se surtían a tiempo, los clientes disminuyeron y con ellos las ventas, surgieron conflictos entre los trabajadores, la tienda no estaba bien surtida y, para completar el cuadro, se empezó a perder material. Los desacuerdos entre hermanos siguieron, pero él se negaba a despedirlo pues no quería dejar en manos de extraños su negocio, al mismo tiempo que la esposa se negaba a aceptar su propuesta de quedarse en la ciudad de México y tomar el control de sus negocios de nueva cuenta.

La situación se tornó insostenible y ante la posibilidad de perderlo todo, la esposa lo convenció de vender la fábrica, sin estar convencido aceptó y la venta concluyó a fines de 1984, en un momento de crisis económica. Con el dinero obtenido liquidó a algunos de sus trabajadores, pagó parte de sus deudas, compró un local y un terreno en Aguascalientes donde construyó una casa más grande para la familia y autos para los hijos. Mientras tanto, sus acreedores y los trabajadores a quienes no pagó la liquidación lo demandaron, aunque esto no obstaculizó que iniciaran una vida de gastos sin reparar en el futuro. Esta situación se prolongó durante varios años y para generar otros ingresos abrió un negocio en su local con venta de artículos para fiestas. El litigio siguió y a principios de los noventa fue obligado a pagar todas sus deudas, por lo que tuvo que vender todas sus posesiones, excepto la casa familiar a nombre de su esposa.

Con lo descrito hasta aquí se puede observar que este grupo familiar tenía una situación de bonanza, resultado de años de trabajo en los cuales había logrado acumular un capital social y económico importante que apoyaba la consolidación de su empresa. Sin embargo, como resultado de un evento familiar inesperado, la situación se modificó drásticamente sin que los cónyuges lograran los acuerdos necesarios para salir adelante. Se optó por descuidar la empresa, que era de donde provenían los ingresos, lo que derivó en una pérdida casi total de recursos económicos, con la única opción de lograr establecerse en un lugar donde sólo tenían el apoyo de la familia, pues sus relaciones comerciales no se habían ampliado, probablemente por su compleja situación legal.

La quiebra de la empresa afectó el carácter del padre, que se volvió taciturno, dejó de trabajar por un largo periodo, por lo que vendieron la casa y compraron otra más pequeña. Como los recursos eran precarios, la esposa pidió ayuda a un familiar que la relacionó con algunos laboratorios y le allanó el camino para que abriera una farmacia en el local que ya tenían, donde separó un espacio que rentó como consultorio, para contar con más ingresos. Como la situación familiar era muy inestable, los hijos sólo concluyeron la preparatoria y tuvieron que empezar a trabajar para tener sus propio dinero. La farmacia fue el único ingreso de la familia durante varios años, ya que el esposo sólo trabajaba ocasionalmen- 
te en negocios como venta de artículos de unicel, para fiestas, etc., sin lograr establecerse en ninguno. A mediados de los noventa las ventas empezaron a disminuir y contrajo deudas con sus proveedores, el dinero escaseaba y apenas contaban con lo necesario para vivir. A fines de 1995 decidió cerrar la farmacia pues la crisis había arrasado con la otra parte del patrimonio familiar, y al año siguiente tuvo que vender el local para acabar de cubrir sus deudas.

Como requería ingresos, rentó un local que se dedicaba a la venta de artículos de decoración, y como "a ella le gustaba eso de decorar y hacer arreglos", decidió incursionar en este rubro con un préstamo hecho por su padre. Mientras tanto su cónyuge seguía con altibajos y ocasionalmente empleado. Fue entonces cuando ella decidió hacerse cargo del hogar, sin reflexionar en las responsabilidades que cada miembro de la familia había tenido en los problemas que enfrentaron. Empezó a viajar a Tonalá, Jalisco, para comprar artículos para su tienda, acompañada de uno de sus hijos, y posteriormente su esposo. En poco tiempo su cónyuge hizo amistad con un artesano que le ofreció enseñarle su oficio, lo que aceptó como una oportunidad de volver a dedicarse a la producción. Rápidamente aprendió a fabricar y cocer piezas y obtuvo un préstamo familiar para la compra de infraestructura mínima para su taller -horno y moldesque instaló en un pequeño terreno en la zona suburbana. El taller estuvo a cargo del padre y uno de los hijos que decidió colaborar con él.

En sus inicios el taller produjo artículos para la tienda, pero era poco lo que ésta requería, por lo que buscó nuevos clientes en la localidad para acomodar toda su producción. Como sus piezas fueron bien aceptadas, se enfocó en éstas pues eran de mayor tamaño -más sencillas de elaborary de más alto precio, por lo que la propietaria de la tienda -y su cónyugeempezó a quejarse de que no le daba prioridad a los artículos que ella requería. Para evitar conflictos llegaron al acuerdo de que los pedidos de la tienda ingresarían junto con otros y tendría que esperar a que le surtieran, asunto que aún en 1999 no se resolvía del todo. El taller se amplió, las ventas mejoraron, contrataron operarios y pagaron el préstamo. En la medida en que el cónyuge se involucró en el negocio la situación familiar mejoró, hasta que vieron la necesidad de obtener un préstamo más para otro horno más grande y herramientas de trabajo. Aunque el cónyuge no era sujeto de crédito, por los problemas legales que tuvo, se había informado correctamente de las opciones ofrecidas para apoyar a las microempresas en Aguascalientes, por lo que convenció a la esposa de que hiciera la solicitud. ${ }^{26}$ Se hizo el estudio de mercado, se otorgó el préstamo, así

\footnotetext{
${ }^{26}$ Él había escuchado en el radio que había programas para apoyar a la microempresa, y a partir de eso buscó información puntual.
} 
como asesoría directa para que el taller y la tienda mejoraran sus procesos. Al momento de la entrevista la situación había mejorado, pero las diferencias respecto de las prioridades se mantuvieron. Para el cónyuge lo importante era el pago del préstamo y contar con recursos económicos para su taller, y para la propietaria adquirir un automóvil, endeudándose de nueva cuenta con su familia.

La exposición de este caso resulta interesante, pues nos permite constatar que para iniciar un negocio, además de contar con los conocimientos y las redes sociales y económicas que le permitan sostenerse, también es necesario llegar a acuerdos entre las partes involucradas que se respeten en el largo plazo. Es evidente que la empresa aun cuando sea idea de una persona, primero es un proyecto familiar donde el núcleo inmediato juega un papel importante para apoyar las decisiones que se deban tomar, y después social, pues incide en la región donde se inserta. Así, el proyecto económico inicial y más sólido que desarrolló el empresario de este caso terminó porque los cónyuges no lograron definir la prioritario para el núcleo familiar. La ambigüedad entre apoyar con el cuidado de los hijos y sostener la unidad de donde provenían los ingresos acabó por aniquilar a esta última y, como consecuencia, entraron en una espiral de fracasos que hasta 1999 no parecía que fuera a repuntar. Aun cuando contaban con un capital económico y habían acumulado un capital social para lograr consolidar su empresa, un desacuerdo doméstico condujo a la anulación de su capital social -expresado en una pérdida de confianza y con ello su capital económico- que no se pudo recuperar. Además de que el empresario quedó fuera del sistema de apoyo como consecuencia del problema legal que enfrentó, como sucedió en el caso precedente a éste. De hecho, al primer evento le sucedió una cadena de errores de estrategia y planificación que se tradujo en obstáculos sistemáticamente insalvables. Ignoro si este tipo de trayectoria tan errática sea un ejemplo poco común, ${ }^{27}$ pero en todo caso, cuando se observa con detenimiento la última fase de la microempresa, se ve que de nueva cuenta no lograrán consolidar su proyecto.

\section{Conclusiones}

Este texto se centró en el análisis de las diferentes y distintivas maneras en que reaccionaron frente a las crisis de 1985 y 1995 un pequeño grupo de empresarios hidrocálidos, propietarios de empresas familiares micro y pequeñas, al tiempo que es un esfuerzo por comprender las razones de

\footnotetext{
${ }^{27}$ En mi experiencia de investigación en tres ciudades distintas no había encontrado una experiencia similar. En razón de esto, consideré que dado que reunía los requisitos necesarios para este ejercicio, había que estructurar el caso y plantearlo.
} 
que esto haya sucedido así y no de otra manera. También se enfocó en el análisis de la trayectoria de sus empresas y en explicar las decisiones tomadas por estos actores económicos en cada ciclo de crisis, con el propósito de exponer lo que sucedió en contextos de inestabilidad económica y por ende qué se puede esperar en el presente en México. Varios aspectos llaman la atención al recapitular sobre lo expuesto. En los casos presentados se puso de relieve la importancia que tienen, por una parte, las prácticas donde se inscribe el actor económico y, por otro, la necesidad de contar, para poder invertir, con un capital cultural y social que sirva de soporte y permita su acumulación y, en consecuencia, genere capital económico. Los casos de éxito, uno relativamente y el otro exitoso, permiten constatar la importancia que tiene contar con un capital cultural, expresado en conocimientos para iniciar un proyecto económico. La existencia de los distintos capitales y su supeditación al capital económico redundan en un beneficio que funciona como una suerte de blindaje frente a las crisis económicas. Ciertamente estas crisis los afectan, y más cuando son de gran envergadura, pero esto tiene un efecto diferenciado en razón de los soportes y apoyos con que cada empresario cuente y con la estructura macro de soporte donde opere. En el primer caso expuesto, se contaba con un capital cultural, pero las prácticas cotidianas y las distintas visiones respecto del papel que jugaba la familia y las relaciones externas se tornaron en un obstáculo difícil de solventar. Adicionalmente, el entorno mayor donde operaba no ofrecía disposiciones de apoyo entre pares, lo que de alguna manera deja al promotor del proyecto en medio de una cierta soledad. Por el contrario, en el segundo caso encontramos la existencia de un capital cultural y uno social en donde se conoce cómo ponerlo en práctica para generar beneficios. Además de operar en un entorno con una infraestructura de soporte orientada a maximizar los beneficios de los involucrados.

Cuando un actor económico promueve la creación de una empresa y puede visibilizar su capital social y hacerlo actuar, produce efectos benéficos para éste, en los campos que son relevantes para su actividad, aun en contextos de crisis económica. En los casos en que esto no sucede, como los últimos dos que se expusieron, la situación que prevalece es errática, con severos altibajos y una pérdida importante de trabajo humano. Se observó que aun cuando el entorno generado por las crisis de mediados de los ochenta y los noventa era adverso, algunos empresarios contaron con los apoyos necesarios y aprovecharon la solidez de las redes que habían conformado para salir fortalecidos del proceso, e incluso con aprendizajes a pesar de las evidentes dificultades que los rodeaban. En otros casos, en cambio, había una evidente carencia de capital cultural para la actividad que se intentaba realizar, lo que generó sucesivas quiebras. 
A pesar de que al principio contaban con recursos económicos, las dificultades para construir un capital social y tomar ventajas de las experiencias de los otros limitaron las posibilidades de desarrollo del proyecto económico. En el último caso analizado encontramos una cierta falta de valoración del capital cultural, expresado en un conjunto de conocimientos que facilitan el avance del proyecto económico, por parte del grupo familiar, además de que las decisiones que el empresario se vio forzado a tomar, prácticamente anularon sus posibilidades no sólo de contar con los distintos capitales, sino con la pérdida de confianza en su propio trabajo. Remontar una situación como la descrita, como se pudo apreciar llevó tiempo, pues el empresario tuvo que empezar a construir un nuevo capital social, revalorar su capital cultural y librar la batalla de las prácticas de su grupo de pertenencia. Es importante enfatizar que los casos analizados dejan ver que quienes se interesan en incursionar en el mundo empresarial son sujetos con trayectorias y experiencias muy diversas y heterogéneas, al igual que son muy distintas las razones que los empujaron a generar sus propios recursos vía una actividad independiente. De igual manera ha sido posible apreciar que la respuesta del aparato estatal, formulada en políticas económicas para estos grupos, cuando llega lo hace tarde para quienes requieren mayores soportes. Para concluir, considero que el entorno social inmediato y el de la estructura social no están construidos para abrir posibilidades de intercambio e interacción en diferentes niveles -en términos de posición de clase-, sino para mantener la separación evidente de espacios sociales. Este proceder funciona entonces como un arnés, que lejos de fungir como una armadura de protección con conocimientos, se torna en un arreo que aísla de los otros.

\section{Bibliografía}

Adler, Paul y Seok-Woo Kwon (2002), "Social Capital: Prospects for a New Concept”, Academy of Management Review, 27 (1), Academy of Management, Nueva York, pp. 17-40.

Barth, Fredrik (1967), "Economic Spheres in Darfur”, en Raymond Firth (ed.), Themes in Economic Anthropology, Holth, Rinehart and Winston, Nueva York, pp. 415-425.

Bourdieu, Pierre (1985), "The Forms of Capital”, en J. Richardson (ed.), Handbook of Theory and Research for the Sociology of Education, Greenwood, Nueva York, pp. 241-258.

Bourdieu, Pierre (1988), La distinción, Taurus, Madrid. 
Bourdieu, Pierre (1997), Razones prácticas: sobre la teoría de la acción, Anagrama, Barcelona.

Coleman, James S. (1993), "The Rational Reconstruction of Society", American Sociological Review, 58, American Sociological Association Washington, pp. 1-15.

Cortés, Fernando (1998), "La distribución del ingreso en México en épocas de estabilización y reforma económica”, tesis doctoral, Centro de Investigaciones y Estudios Superiores en Antropología Social-Universidad de Guadalajara.

Curran James y Roger Borrows (1987), "The Social Analysis of Small Business: Some Emerging Themes", en Robert Goffee y Richard Scase, Entrepreneurship in Europe, The Social Processes, Crom Helm, Londres, pp. 164-191.

Goffee, Robert y Richard Scase (1985), Women in Charge. The experiences of Female Entrepreneurs, George Allen and Unwin Publishers, Londres.

Implan (Instituto Municipal de Planeación) (2004), Competitividad económica de la ciudad de Aguascalientes, 1990-2004, <www.cideu. org/site/go.php?id=2766>, 9 de septiembre de 2009.

Martinelli, Alberto (1994), "Entrepreneurship and Management", en Neil Smelser y Richard Swedberg (eds.), The Handbook of Economic Sociology, Princeton University Press-Russel Sage Foundation, Nueva York, pp. 476-503.

Martínez, José Octavio (1995), "Política macroeconómica, reforma estructural y empresas", en Thomas Calvo y Bernardo Méndez Lugo (eds.), Micro y pequeña empresa en México, Centro de Estudios Mexicanos y Centroamericanos, México, pp. 19-50.

Polanyi, Karl (1968), “The economy as Instituted Process” en Eduard E. LeClair Jr. y Harold Schneider (eds.), Economic Anthropology Reading in Theory and Analysis, Holt, Rinehart and Winston, Nueva York, pp. 122-143.

Portes, Alejandro (1999), "Social Capital: Its Origins and Applications in Modern Sociology”, Annual Review of Sociology, 24, Annual 
Review, A NonProfit Scientific Publisher, Palo Alto, Cal., pp. $1-24$.

Portes, Alejandro y Patricia Landolt (2000), "Social Capital: Promise and Pitfalls of its Role in Development", Journal Latin American Studies, 32, Cambridge University Press, Cambridge, pp. 529-547.

Salmerón-Castro, Fernando (1996), Los intermediarios del progreso. Politica y crecimiento económico en Aguascalientes, Centro de Investigaciones y Estudios Superiores en Antropología Social, México.

Serna, María Guadalupe (2002), "La actividad empresarial femenina en México: las últimas tres décadas", El Mercado de Valores, 1, año LXII, Nacional Financiera, México, pp. 3-12.

Serna, María Guadalupe (2003), "Aqui no hay seguro contra crisis..." Empresarias, empresas y hogares en dos zonas metropolitanas de México, Centro de Investigaciones y Estudios Superiores en Antropología Social-Instituto Mora, México.

Recibido: 5 de noviembre de 2009. Reenviado: 13 de octubre de 2010. Aceptado: 3 de mayo de 2011.

María Guadalupe Serna. Es doctora en ciencias sociales, con especialidad en antropología social, por el Centro de Investigaciones y Estudios Superiores en Antropología Social (CIESAS) y maestra en estudios latinoamericanos por la Universidad de Texas, en Austin. Es profesora-investigadora en el Instituto de Investigaciones José María Luis Mora y miembro del Sistema Nacional de Investigadores, nivel I. Sus líneas de investigación se han enfocado en el análisis de las micro y pequeñas empresas mexicanas encabezadas por mujeres, la formación de redes y capital social, la inserción laboral femenina en nuevos territorios (managment y alta dirección), la responsabilidad social empresarial y la ciudadanía corporativa. En los últimos años también ha incursionado en el análisis de organizaciones sociales y procesos de solidaridad. Entre sus publicaciones en los temas de empresa destacan, "Aqui no hay seguro contra crisis..." Empresarias, empresas y hogares en dos zonas metropolitanas de México, CIEsAsInstituto Mora, México (2003); "Mujeres y opción empresarial: respuestas a una encrucijada", en Sara Elena Pérez-Gil y Patricia Ravelo (eds.), Voces disidentes. Debates contemporáneos en los estudios de género, Cámara de 
Diputados LIX Legislatura-CiEsas-Miguel Ángel Porrúa, México, pp. 355-396 (2004); "Empresarios y ejecutivos en la ciudad de México", en Marisol Pérez Lizaur (coord.), Los ejecutivos de alto nivel ¿Una élite global?, Universidad Iberoamericana, México, pp. 57-86 (2005); "Las cartas sobre la mesa. Hacia la discusión pública de las decisiones en investigación", en Graciela de Garay (coord.), Aproximaciones teórico-metodológicas y experiencias empiricas, Instituto Mora, México, pp. 131-154 (2007). 